\title{
Cryptocarbon: the promises and pitfalls of forest protection on a blockchain
}

\begin{abstract}
In this commentary, we explore how blockchain is being leveraged to address the fundamental problems with market-based forest protection globally. In doing so, we consider the ways 'cryptocarbon' initiatives are creating new challenges that have so far escaped critical scrutiny. A blockchain is a distributed and immutable electronic database - a ledger of every transaction that has ever taken place on a network, with the data stored as cryptographically secured blocks, strung together in a chain. The technology is being increasingly hyped as applicable for a whole range of industries, social service provisions, and environmental management concerns. This includes the facilitation of natural asset market mechanisms, like Reducing Emissions from Deforestation and Forest Degradation (REDD+). The original aim of REDD+ was to incentivise conservation, making tropical forests more valuable standing than cut down. Multiple factors, including lack of consumer interest, created a deluge of supply. Ninety-five percent of the world's avoided deforestation credits, representing millions of hectares of conserved forest, were stuck without a buyer. Several flagging REDD+ projects are now hoping that blockchain technology can carry them to new heights of market capitalisation. However, like with any powerful new technology, the benefits remain ambiguous.
\end{abstract}

\section{Keywords:}

Cryptocarbon; Cryptocurrencies; Blockchain; REDD+; Carbon offsetting; Forest Conservation. 


\section{Introduction}

Tropical forests play a key role in the global carbon cycle. Any global fix for mitigating human-induced climate change will likely fail, unless their protection and restoration are included (Sunderlin et al., 2012). Market-based mechanisms, such as the Reducing Emissions from Deforestation and Forest Degradation (REDD+) programme, remain a cornerstone technical fix, providing economic incentives to make forests more valuable standing than cut down. However, 20 years after the Kyoto Protocol established the first international carbon market system, and 10 years after REDD+ was first envisaged, the failure of carbon markets has become clear. Despite the ability of market-based mechanisms to disingenuously account for some national emission reductions (see Schneider \& Kollmuss, 2015), global $\mathrm{CO}_{2}$ concentrations have not been as high as they are today since at least the advent of the Paleocene-Eocene Thermal Maximum, about 66 million-years ago (Zeebe et al., 2016). In 2017, the carbon market price for offsetting the average annual carbon footprint in the UK was $f 18$ (GBP) (\$23 USD). Some externally validated offset outfits offer the same service for just 35 pence (Hamrick, 2017). The economic benefits of these endeavours, at such bargain-basement prices, inevitably fail to trickle down to those who produce forest carbon commodities. Due to these and many other shortcomings, some are confirming that "REDD is dead, it is time to cut our losses and move on" (Redford, 2013 p437; see also Fletcher et al., 2016). However, despite carbon market failures to enable reductions in atmospheric $\mathrm{CO}_{2}$, or in distributing costs and benefits equitably, market-based approaches to conservation are steadily growing in significance (World Bank, 2017). New emissions trading schemes like China's (van de Gaast et al., 2018), as well as international carbon offsetting obligations for airlines ${ }^{1}$, are keeping REDD+ relevant (Labbate, 2017). New technical devices, including cryptocurrencies and blockchain, are also offering a lifeline to existing REDD+ projects.

A blockchain is a distributed and immutable electronic database - a ledger of every transaction that has ever taken place on a network. This data is stored as cryptographically secured 'blocks', strung together in a chain. While the cryptocurrency, Bitcoin was the first application of blockchain technology, Bitcoin should not be used to mean blockchain, which is a much broader idea. Cryptocurrencies are but one use of the technology. Blockchain also has capabilities far beyond any ordinary financial or natural capital asset database ${ }^{2}$, because the technology uses algorithms to provide a secure mechanism for electronic collaboration that does not rely upon a central authority for assets to be trusted (Al-Saqaf \& Seidler, 2017). In short, actors who do not necessarily trust each other can trust the authenticity of information held in this shared database. Although blockchain platforms may use different means of validating data ('consensus protocols'), they all use the same general approach based on a decentralised peer-to-peer (P2P) network accommodating a theoretically permanent, tamper-proof ledger of every transaction that has ever taken place among users (Huckle \& White, 2016). The technology is challenging traditional finance and accountancy, and expanding into other areas of business and public policy. Now, despite historical failures of carbon markets, some are suggesting the technology offers to revolutionise the world of climate-finance, including results-based payments for REDD+ (Connolly et al., 2017). There is a lot of hype around the potential for transforming the smoke and mirrors world of carbon offsetting (see Marke et al., 2018). There is also scepticism (Lang, 2018; Sullivan, 2018).

\footnotetext{
${ }^{1}$ The International Civil Aviation Organisation (ICAO) has committed to establishing a carbon emissions market for international aviation by 2021. Also known as CORSIA (Carbon Offsetting and Reduction Scheme for International Aviation), the market is expected to take advantage of REDD+ commodities (Labbate, 2017).

${ }^{2}$ The European Union Transaction Log (EUTL) is an example of a non-blockchain-based, centrally-administered carbon registry that checks, records, and authorises all transactions taking place between accounts as part of the EU Emissions Trading Scheme (ETS).
} 
Like with any powerful new technology, the benefits of forest protection on a blockchain remains ambiguous. The following sections consider how blockchain enables various opportunities for proponents of market-based environmentalism, as well as fundamental challenges for wider conservation movements. We begin by assessing four of the ways blockchain is being leveraged to engage the persistent faults of REDD+. We then focus on the environmental governance issues relating to existing and proposed cryptocarbon projects, highlighting why the conservation applications of blockchain technology deserves the scrutiny of critical scholars. We conclude with some recommendations for future research.

\section{REDD+ faults and cryptofixes?}

REDD+ has morphed considerably from how it was originally conceived. The mechanism continues to be tweaked, receiving bolt-on components to overcome inherent limitations. The Centre for International Forestry Research (CIFOR) has defined REDD+ in two ways:

A broad definition [...] holds that REDD+ comprises local, subnational, national and global actions whose primary aim is to reduce emissions from deforestation and forest degradation and enhance carbon stocks (increase removals) in developing countries. A narrower definition is that REDD+ also includes results-based or conditional payments, which was a core idea when REDD+ was launched at the 2007 climate talks in Bali (Angelsen et al. 2012: 381).

REDD+ was to stand out from other well-established Payments for Ecosystem Services (PES) methodologies. The mechanism was designed to enable the formation of scaled-up forest protection projects in almost every tropical forested country, with long-term stringent monitoring, reporting and verification requirements (McGregor, 2010). The 'services' to be delivered, primarily in the form of avoided emissions from deforestation or 'saved carbon', were to be sold through a market as compliance market offsets, for countries with emission reduction targets, as well as through voluntary markets (Howson, 2014). Compliance offsets provide a cheaper alternative to actual emissions reductions (which would involve investing in low-carbon technologies, for example).

The weaknesses of REDD+ have become clear in recent years. Technological as well as social and environmental justice concerns, have led some to argue that REDD+ represents another conservation fad, driven primarily by NGOs and their institutional needs to secure donations (Redford et al., 2016; Lund et al., 2017). Others argue that the weaknesses are not fundamental to its operation (McGregor et al, 2014), and that REDD+, although troubled, remains a cornerstone mechanism for protecting the world's forests (Angelson et al., 2016). Technical tweaks are all that is required (Duchelle et al, 2018). The rise of blockchain is inspiring techno-ecological innovations, which we argue, are attempting to paper over the cracks of four key interlinked mechanical faults. These include: 1) lack of public interest leading to unsustainable funding, 2) deficient Monitoring, Reporting and Verification (MRV) regimes, 3) inequitable distribution of project costs and benefits, and 4) failure to secure rights for forest dependent and indigenous communities. The remainder of this section will explain how these faults and their respective crypto-fixes are playing out in practice.

\section{Fault 1: REDD+ project funding is limited and unsustainable}

Low demand for carbon credits and low carbon prices in an already volatile carbon market has meant that possible REDD+ funding streams are far too limited to support the hundreds of projects 
contending for consumer attention (Gizachew et al., 2017). Indeed, the instability and poor reliability of sustainable sources of private finance has proved a major hurdle for REDD+ uptake (Dixon and Challies, 2015). While REDD+ was originally conceived as something that would be funded by a massive global carbon market (McGregor, 2010), this vision no longer reflects reality. The majority of all avoided emissions remain unsold, causing a continued saturation in supply. Only a tiny proportion of over 330 REDD+ initiatives around the world have been able to access payments directly from any carbon market (Evans, 2017).

Some blockchain-based projects are actively addressing REDD+ funding issues, while others are in earlier stages of development. These interventions range from offering REDD+credits in exchange for popular cryptocurrencies, to enabling automated payment protocols - transforming carbon credits into exchangeable tokens. However, these blockchain-based REDD+ funding platforms are problematic. Projects aimed at enabling transactions of carbon credits using Bitcoin, such as Cool Earth's Offset-Bitcoin project, produce a significant carbon footprint. Bitcoin's consensus protocol (known as Proof-of-Work or PoW) necessitates an ever-increasing hash rate - the amount of computing power needed to maintain the network (Huckle and White, 2016). Currently, each Bitcoin transaction has a carbon footprint of $400 \mathrm{~kg} / \mathrm{CO}_{2} \mathrm{e}^{3}$. A single Bitcoin transaction is equivalent to 450,000 VISA transactions (Digiconomist, 2018). Mora et al. (2018) suggest that Bitcoin emissions alone could increase average global temperatures by more than $2^{\circ} \mathrm{C}$, over the next 30 years. Despite the inherent contradiction of offsetting emissions with something so energy intensive, there are clear benefits for REDD+ project implementers to receive funds in cryptocurrencies. The project receives payments without suffering 'frictional losses' - the necessity to share funds received with host governments, brokers, NGOs, or other intermediaries. Organisations such as BitGive and BitHope for example, facilitate traceable transactions to projects using widely circulated cryptocurrencies like Bitcoin and Ethereum for this reason (KFNX, 2018) (see Table 1).

\begin{tabular}{|c|c|c|c|c|}
\hline $\begin{array}{l}\text { Token / } \\
\text { project }\end{array}$ & Developer & Blockchain & Established use case & $\begin{array}{l}\text { Current } \\
\text { Development } \\
\text { Phase (2018) }\end{array}$ \\
\hline CarbonCoin & $\begin{array}{l}\text { CarbonCoin } \\
\text { Ethereum CCE }\end{array}$ & Ethereum & $\begin{array}{l}\text { The coin is a more energy-efficient cryptocurrency } \\
\text { compared with Bitcoin. A percentage of funds } \\
\text { raised from coin sales are spent on forest } \\
\text { protection and reforestation projects. }\end{array}$ & $\mathrm{ICO}$ \\
\hline $\begin{array}{l}\text { CGRID } \\
\text { tokens }\end{array}$ & $\begin{array}{l}\text { Carbon Grid } \\
\text { Protocol }\end{array}$ & Ethereum & $\begin{array}{l}\text { The platform creates a framework to reward } \\
\text { blockchain networks and DApps for offsetting their } \\
\text { carbon footprint. Carbon Grid Protocol (CGRID) } \\
\text { acts as a complementary protocol layer enabling } \\
\text { efficient access to carbon credit markets. }\end{array}$ & Pre-sale \\
\hline CarbonX & $\begin{array}{l}\text { CarbonX Inc. / } \\
\text { Zerofootprint }\end{array}$ & Ethereum & $\begin{array}{l}\text { The 'Zerofootprint' program assesses the carbon } \\
\text { impact of products and services, then balances that } \\
\text { impact with carbon offsets to certify the carbon } \\
\text { neutrality of products and services. The } \\
\text { 'GOODcoins' program further engages consumers } \\
\text { by rewarding them for purchasing Zerofootprint } \\
\text { certified products. }\end{array}$ & Unknown \\
\hline
\end{tabular}

\footnotetext{
${ }^{3}$ At the end of 2018 the energy needed to carry out a single Bitcoin transaction had a carbon footprint equivalent to a return flight from London to Moscow (https://www.carbonfootprint.com/calculator.aspx). In 2018 the Bitcoin network used 74 TW/h of electricity, maintaining an annual carbon footprint of 35,830 kt of $\mathrm{CO}_{2} \mathrm{e}$ - equivalent to that of the Philippines.
} 
$\begin{array}{ll}\text { Climatecoin } & \begin{array}{l}\text { Climatecoin } \\ \text { CO2 }\end{array} \\ \text { Foundation } & \text { Ethereum }\end{array}$
The platform allows consumers and retailers to purchase carbon credits using micro-payments from a non-specific 'carbon credit pool'.

\begin{tabular}{|c|c|c|c|c|}
\hline Earth Dollar & $\begin{array}{l}\text { Earth Dollar } \\
\text { Alliance }\end{array}$ & $\begin{array}{l}\text { Bitcoin Air } \\
\text { \& Peercoin }\end{array}$ & $\begin{array}{l}\text { The token claims to be the first 'dual-chain } \\
\text { bilaterally operating Blockchain'. By forking the } \\
\text { Bitcoin blockchain, and merging it with the } \\
\text { Peercoin, Earth Dollars produce a dual-chain } \\
\text { Blockchain with one end accessible to exchanges, } \\
\text { trading, and sending, while the other chain is } \\
\text { internal, and backed by 'Carbon Credit Assets'. }\end{array}$ & Pre-sale \\
\hline EarthToken & $\begin{array}{l}\text { Impact Choice } \\
\text { - Kariba REDD+ } \\
\text { project, } \\
\text { Zimbabwe }\end{array}$ & Ethereum & $\begin{array}{l}\text { The platform allows consumers and retailers to } \\
\text { cost and purchase carbon credits using micro- } \\
\text { payments. }\end{array}$ & ICO \\
\hline $\begin{array}{l}\text { Green List } \\
\text { Standard } \\
\text { Token }\end{array}$ & IUCN & Ethereum & $\begin{array}{l}\text { The IUCN Green List programme provides a } \\
\text { standardised assessment regime for the } \\
\text { performance of protected and conserved areas and } \\
\text { to fairly distribute costs for their evaluation. } \\
\text { Assurance for the credibility of the programme will } \\
\text { be supported by mapping the Green List process on } \\
\text { the blockchain, creating a token which can then be } \\
\text { used to run smart contracts for Green List } \\
\text { candidate nature areas. }\end{array}$ & Unknown \\
\hline Ocean & $\begin{array}{l}\text { Poseidon } \\
\text {-Cordillera Azul } \\
\text { REDD+ project, } \\
\text { Peru }\end{array}$ & Stellar & $\begin{array}{l}\text { The platform allows consumers and retailers to } \\
\text { purchase carbon credits using micro-payments } \\
\text { from various Ecosphere+ REDD+ projects around } \\
\text { the world. }\end{array}$ & ICO \\
\hline $\begin{array}{l}\text { Offset } \\
\text { Bitcoin }\end{array}$ & Cool Earth & Bitcoin & $\begin{array}{l}\text { The Cool Earth platform's goal is to offset a greater } \\
\text { amount of } \mathrm{CO}_{2} \text { than the amount released by the } \\
\text { Bitcoin network, by purchasing carbon credits from } \\
\text { Cool Earth projects in Peru, DRC and PNG. If } \\
\text { successful, the overall impact of the Bitcoin } \\
\text { network shifts from negative to positive. }\end{array}$ & Active \\
\hline Regen & Regen Network & Ethereum & $\begin{array}{l}\text { Regen Ledger is a platform that simultaneously } \\
\text { serves as a 'true cost accounting machine', an } \\
\text { 'ecological data marketplace', a 'distributed } \\
\text { computational network', and a 'biospheric } \\
\text { monitoring device'. }\end{array}$ & Pre-sale \\
\hline Verde & $\begin{array}{l}\text { Veridium Labs / } \\
\text { Infinite Earth } \\
\text {-Rimba Raya } \\
\text { REDD+ Project, } \\
\text { Indonesia }\end{array}$ & IBM / Stellar & $\begin{array}{l}\text { The platform enables purchases of carbon credits } \\
\text { using micro-payments from the Rimba Raya } \\
\text { Reserve, Indonesia. Veridium offers a rewards } \\
\text { debit/credit card that will allow consumers to make } \\
\text { 'EcoSmart- Purchases }{ }^{\mathrm{TM}} \text { '. The VERDEPAY'⿳亠口冋口灬 } \\
\text { debit/credit Rewards card automatically offsets the } \\
\text { environmental footprint of everything purchased } \\
\text { on the card. Additionally, through its Rewards } \\
\text { program, cardholders will receive VERDE as a 'Cash } \\
\text { Back' on every transaction. }\end{array}$ & $\begin{array}{l}\text { Private sales } \\
\text { only }\end{array}$ \\
\hline
\end{tabular}

Table 1: Examples of cryptocarbon projects and their respective features 
Similar repudiation is required when a blockchain is used to transform carbon credits into tradable tokens. The process of conjuring value is unique to each token. Some of these tokens are similar to currencies, others are more like securities, and others have properties that are entirely new (Conley, 2017). Some REDD+ projects, including Rimba Raya's Veridium project, are selling tokens speculatively, like shares in a new company, as part of an Initial Coin Offering (ICO). Other projects, such as Poseidon and Ecosphere+, give tokens as an incentive to people offering their computer power to host the platforms' distributed ledger. As with any commodity, the value of a cryptographic token is not natural or permanent (Appadurai, 1994). Bitcoins are theoretically valuable as representations of the computer processing 'work' that went into their production, as well as their theoretical scarcity, and their utility as a medium of exchange (Li and Wang, 2017). Ether, Ethereum's 'smart-contract' ${ }^{4}$ token is valued as the currency used to purchase the services of a particular application (Evans, 2017). In contrast, the value of a cryptocarbon token is derivative, literally derived from the value of the underlying avoided emissions, and other REDD+ co-benefits. However, as Buscher (2010) argues, the problem with producing 'derivative nature' in this way, is that forests, people and livelihoods are arranged as 'underlying assets' for the 'real' source of value of neoliberal conservation. Despite offering an immutable and 'trustworthy' (with regards to maintaining consensus between contracting parties), efficient and accessible means of carbon commodity exchange, cryptocarbon tokens are not capable of representing the materiality of 'saved carbon'. These underlying 'assets' are a fetishised abstraction of 'nature' in both image and value (Nel, 2015). Blockchain cannot fix that.

\section{Fault 2: REDD+ projects fail to accurately monitor, report and verify forest carbon attestations}

Due to the dynamic nature of forests, REDD+ projects cannot attest to permanent removals of atmospheric carbon. Milne et al. (2018) problematize the overly simplified codification systems used to quantify REDD+ project attestations that are elusive, ethereal and non-permanent in nature. As explained by Angelsen, et al. (2012), issues with representing dynamic forest eco-systems stem from the methods used to predict and model future conjectural deforestation patterns, the quality of data for constructing reliable historical deforestation rates, and the use of non-permanent carbon stock sampling plots. Despite some gains in satellite technology, numerous methodological problems involved in quantifying the emissions saved through REDD+ projects continue (Green, 2018). This includes problems identifying and agreeing baselines or reference levels.

Blockchain-based applications aim to improve the reliability of carbon sequestration monitoring. For example, FlowerTokens ${ }^{5}$ are an experimental project centred on the verification and representation of specific plants, to create a combined crypto-collectible physical asset ${ }^{6}$. FlowerTokens are part of a series of projects oriented around the production of 'hybrid ecosystems' - a mixture of cryptocollectibles and verified, physical, constantly updated securities. During the development phase of the project's implementation, users can buy, trade, and speculate on tokenised Freesias (familie Iridaceae) within an online marketplace. The token is a representation of an individual flower, with each token

\footnotetext{
${ }^{4}$ A blockchain, like Ethereum, is programmable around 'smart contracts' that use conditional triggers for certain events, i.e. If $x$ happens, execute $y$.

${ }^{5}$ https://flowertokens.terra0.org/info/

${ }^{6}$ CryptoKitties.co are a good example of crypto-collectable digital assets, also known as NFTs (non-fungible tokens). These digital artworks are near impossible to replicate, making the work scarce, and therefore collectible.
} 
linked to data generated by a 'camera oracle" ${ }^{\text {" }}$. The state of the individual tokens are automatically updated according to the different phases of the corresponding plant's growth and decline (Terra0, 2018).

Although unquestionably creative, many cryptocarbon experiments are not new, but instead offer cryptographic re-runs and modular replacements for previous experiments in REDD+. Blockchain experimenters, Gainforest ${ }^{8}$, have developed an application to verify threatened patches of forests and attestations of 'caretaker' action through 'Proof-of-Care' protocols. However, instead of identifying threatened forests based on convenience - a common criticism of many REDD+ schemes to date (Lin et al., 2014) - Gainforest uses algorithms to predict areas-at-risk in order to prioritise sites for intervention. Using the Gainforest platform, donors can pledge any amount, which is distributed to forest caretakers. Donors can also see where and when their support impacts conservation efforts in real-time using smart-contract distribution systems.

Some blockchain projects have abandoned the unfeasible task of forecasting future deforestation patterns, instead focussing on the remediation of already degraded land, and incentivising 'Changeof-State'. Regen Network ${ }^{9}$ proposes to use a series of 'Ecological State Protocols' to monitor on-theground conditions and generate more reliable attestations about the material health of any predefined geographical area. According to Regen, the core set of protocols and remote sensing tools have been co-produced by working groups of scientists, ecologists, farmers, and community members, and will be open source (Regen Network, 2018) (see Figure 1).

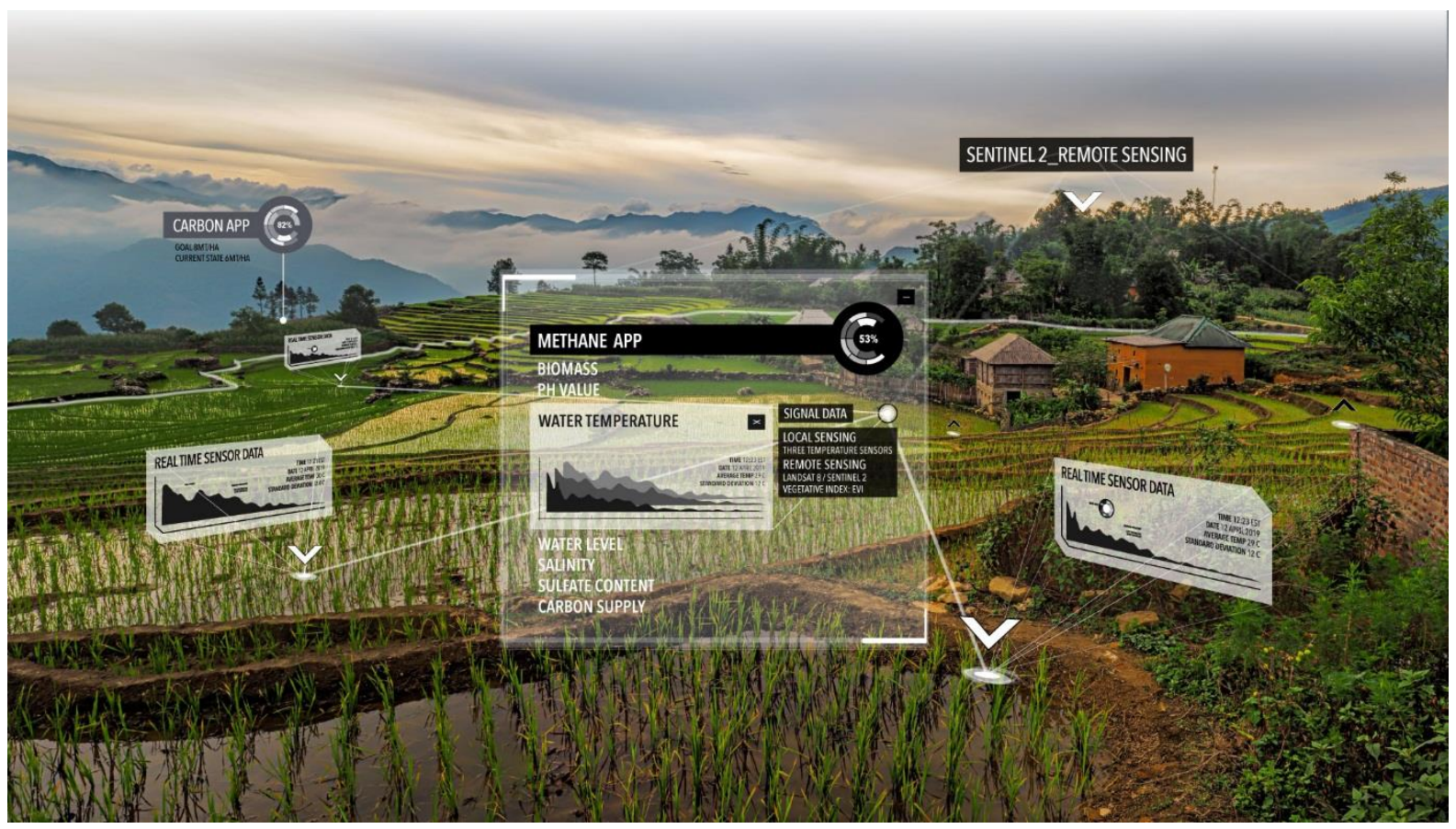

Figure 1: Model of Regen Network's Integrated Ecological State Protocols

\footnotetext{
${ }^{7}$ For the blockchain to access data from outside the network, the system uses an array of cameras to monitor and measure the plant. External data triggers smart contract executions when pre-defined conditions are met.

${ }^{8} \mathrm{http}: / /$ gainforest.org/

${ }^{9} \mathrm{http}: / /$ www.regen.network/
} 
Regen and Gainforest propose fully automated carbon offset initiatives that utilise self-executing code governed by smart-contracts. To help prevent fraudulent behaviour, monitoring, reporting and verification of all carbon storage attestations are decentralised and remotely operated. Remote sensing tools include RaDAR and LiDAR, but also depend on 'Proof-of-Location' (PoL) devices, sometimes known by the ominous term, Sentinels.

Sentinels linked to blockchain-based incentive distribution infrastructures depend on the Internet of Things (IOT), networks of smartphones and other devices embedded with electronics, software, sensors, actuators, and connectivity. Companies, like XYO Network ${ }^{10}$ and FOAM ${ }^{11}$, have built open protocols to enable devices to connect, triangulate and exchange data for forest conservation projects. According to FOAM, their protocols are designed to empower users to build consensus-driven maps that can be trusted for every application. The goal of the PoL solution is to provide the framework and infrastructure to support a decentralised, privacy-preserving, highly accurate, censorship resistant alternative to GPS (FOAM, 2018).

Many REDD+ interventions, ostensibly designed to promote reforestation have, in some cases, accelerated biodiversity loss by providing perverse incentives for unsustainable management and conversion of natural forests to monoculture landscapes (Barr and Sayer, 2012). Deep learning Artificial Intelligence (Al) technology, or Artificial Neural Networks, are being 'trained' to know the difference. For example, according to Boyda et al. (2017), the D-Wave Al platform is $90 \%$ accurate at recognising a range of tree species from aerial photographs. This demonstrates how computers can be programmed to look at and analyse images. iNaturalist ${ }^{12}$ is launching a deep-learning-based app that automatically identifies plants and animals by species. The application identifies and learns patterns from photos uploaded by users of their website that have been verified by their community of experts and amateur 'citizen scientists'. However, these intelligent monitoring algorithms are encoded with human prejudice. As O'Neil (2016) explains, algorithms are simply opinions framed as math, dependent upon a historical data-set and an 'objective function' - an idea of what constitutes success. There is therefore no objective algorithm, because the interests that build an algorithm, define success. The interests of capital are coalescing with blockchain algorithms, 'big data', and Al in the monitoring, reporting and verification of the environment. This will inevitably lead to an expansion of capitalist interests, at the expense of sound environmental management.

\section{Fault 3: REDD+ project benefits are inequitably distributed}

Regen and Gainforest do not clearly specify how they intend to identify and verify appropriate 'caretakers' to participate in their incentivisation programmes. For many REDD+ schemes, in the absence of formal tenure and 'carbon rights' regimes, participation has often been mediated through social relationships, technical knowledge and access to local markets and capital (Karsenty et al., 2014; Howson, 2015). Many projects have proved highly exclusive with benefit-sharing frameworks disproportionately excluding women and other already marginalised groups (Cavanagh and Benjaminsen 2014; Nel 2015; Howson, 2018). Projects have also proved expensive with project funding generally only covering the cost of project inception. Land concessions and associated licensing fees often swallow up the lion's share of available funds. Enrici and Hubacek (2018) report such fees in Indonesia to range from US\$0.6 million to US\$1.4 million. Third party intermediaries

\footnotetext{
${ }^{10}$ https://xyo.network/

${ }^{11}$ https://foam.space/

12 https://www.inaturalist.org/
} 
including officials, auditors, verifiers, consultants and scientific experts, who ensure REDD+ baseline levels are believable, are also expensive and absorb much of the residual capital (Gupta et al., 2012).

In many contexts where conventional, non-blockchain-based REDD+ projects have been implemented, payments have never made their way to the forest dependent communities, who pay the highest cost and take on the highest levels of risk (Howson and Kindon, 2015; Nel, 2015; Enrici and Hubacek, 2018). Payments have typically been made in-kind as community development assistance (Milne and Niesten, 2009). Fintech solutions for REDD+ benefit sharing regimes, in the form of mobile money platforms, are being proposed to enable small-holders and other rural actors to access economic benefits. Thompson (2017) points out that several countries including Cambodia, China, Tanzania, and the Philippines demonstrate both high REDD+ uptake, and high 'e-money' penetration. Using existing mobile technology infrastructure in these rural locations lowers transaction costs, enables higher frequency payments, and could provide new socioeconomic benefits to those with the capacity to participate.

Thomason et al. (2018) suggest that leveraging blockchain and distributing payments using digital 'crypto-wallets' might go further, offering opportunities to access some of the financial benefits of protecting forests for the most vulnerable. The authors provide several case-study examples of how this works in practice, in Papua New Guinea, Swaziland, Somalia, Armenia, and Samoa. Through the orchestration of Decentralised Autonomous Organisations (DAO) ${ }^{13}$, information from remote monitoring sensors use verification protocols and automatically dictate the allocation of resources among a group of rural individuals (DuPont, 2017). However, issues around digital exclusion have, so far, been largely ignored. As Warren (2007) points out, there is a danger that in rural areas, non-users of communication technology will become disenfranchised by such developments, and these include some of the most disadvantaged and vulnerable sections of rural society. Our own research in the forests of Central Kalimantan also highlights the damaging social and environmental effects of privileging those with REDD+ access capabilities while ignoring those without (McGregor et al., 2014; Howson, 2018).

There are also unresolved issues surrounding the conditionality and programmability of forest protection incentive tokens. Blockchain is changing the way aid agencies provide assistance, including tokenised cash transfers, to the use of biometrics to register and track beneficiary assistance through iris scans and fingerprinting (Sandvik and Raymond, 2017). Cryptographic tokens such as AidCoins ${ }^{14}$ for example, are fully programable to ensure donations are spent 'correctly' (AidCoin, 2018). Oxfam Australia are also exploring the potential for similar tokens to enable programmable payments to individuals and organisations during disaster events in the Pacific (Hallwright \& Carnaby, 2018). Cryptocarbon token transactions, and, potentially, the economic life of individuals living in remote rural locations, could be monitored, managed, and even switched-off remotely, to ensure transactions occur as intended by the project implementers.

\section{Fault 4: REDD+ projects fail to secure the rights of forest dependent and indigenous communities}

REDD+ projects have often failed to generate improvements in well-being for participating stakeholders (Sunderlin et al., 2017). Projects have undermined indigenous rights (Krause, 2013), and

\footnotetext{
${ }^{13} \mathrm{~A} D A O$ is a pseudo-legal organisation in which participants automatically respond to inputs according to preprogrammed rules.

${ }^{14}$ https://www.aidcoin.co
} 
perpetuated securitisation and violence by government actors (Cavanagh et al., 2015). Carbon projects can often promote adversarial relationships within and between indigenous groups, encouraged through a market-based REDD+ that relies on well-defined property rights (Farley \& Costanza, 2010). Even in cases where indigenous land tenure has been secure and risk of dispossession minimal; such market-based undertakings have presented a tendency toward exclusionary management practices (Sullivan, 2009). Yet, for most carbon offset projects, a regulatory framework of safeguards operates in order to manage potential social and economic risks (Jagger et al., 2012). These risks include involuntary displacement of forest dependent and indigenous peoples from their land, as well as other rights violations. However, REDD+ projects that operate best-practice safeguards, often fail to pay attention to the specificity of socio-cultural, historical, and political contexts, which aggravates already complex land access and tenure regimes in the Global South (Barletti and Larson, 2017). This lack of clear and exclusive tenure rights in places, continues to be identified as a key failing of many market-based approaches to forest conservation (Larson et al., 2013).

In much of the Global South, uncertainty around land holding is common, as are disputes over titles and accusations of pervasive state corruption (Kshetri, 2017). Blockchain-based applications have been developed to enable land titling systems that are more efficient, transparent and theoretically immune to corrupt practices. For example, multiple states in India have switched to blockchain technology to record land deals (Oprunenco and Akmeemana, 2018). According to Bar (2017), due to a lack of coordination between various registering agencies handling land records in India, the information registered is not standardised. This leads to ambiguity in terms of the nature of rights being transferred by the transaction and the boundaries of the land being transacted. Records are not updated promptly and entries rarely reflect the true nature of ownership of a particular parcel of land. In 2015 , India was facing a backlog of 124,325 cases for property registration. The governments of Honduras, Georgia and Rwanda have faced similar challenges, also spurring the development of blockchain-based land-titling solutions (Mwanza and Wilkins, 2018).

The Terra0 blockchain project takes advantage of the way these blockchain-based land registries fail to differentiate between individual, corporate, or even non-human entities as specified owners of land (Gloerich et al, 2018). Their artistic intervention furnishes forests with agency to own and protect themselves. Conceptions of ownership and agency are commonly associated with intentionality of human actors, who exert control through their decision-making, strategies and behaviour. However, recent work around carbon's socio-natural configurations, consider the agency of carbon more in terms of the sets of relations that produce particular outcomes and enable the ability of these configurations to shape the world (McGregor et al, forthcoming). With blockchain applications, such as autonomous policy decision making tools (see Kiggins, 2018) agency extends beyond the human, as it no longer requires conscious decision-making. Instead, agency derives from material relations between things, or what Bennett (2010) refers to as 'thing-power'. Exploiting autonomous land registries, the Terra0 project offers carbon its thing-power, expressed on human-terms. Terra0's white paper states:

Terra0 is a self-owned forest; an ongoing art project that strives to set up a prototype of a self-utilising piece of land. Terra0 creates a scenario whereby a forest is able to sell licences to log trees through automated processes, smart-contracts and blockchain technology. In doing so, this forest accumulates capital. A shift from valorisation through third parties, to a self-utilisation, [which] makes it possible for the forest to procure its 
real exchange value, and eventually buy (thus own) itself. The augmented forest, as owner

of itself, is in the position to buy more ground and therefore to expand.

These human terms are based on private property relations. Terra0, and projects like it, constitute an opportunity to subvert 'natural resource' chattelism. They may also constitute cooptation of new materialisms, ideas and discourses to mask 'green growth' strategies of accumulation. In the following section we consider the implications of all this automation for REDD+ decision making frameworks.

\section{Governing cryptocarbon}

Automated cryptocarbon platforms can remove the necessity to trust third parties, and in doing so render traditional forms of REDD+ governance obsolete. For conventional REDD+ projects, the most obvious source of governing authority is the various private voluntary carbon standards, which verify emissions reductions and certify project compliance with social and ecological safeguards (Dixon \& Challies, 2014). Though verified REDD+ offsets retain traceability to originating projects, mistrust in the state and non-state entities that trace these commodities has been highlighted as the missing building block for the programme's success (Iley and Elvers, 2017). For carbon offsets to be trusted, Chapron (2017 p403) argues that algorithms should replace the humans that repeatedly fail to be trustworthy. For environmental markets, he argues, "[t]he time is ripe for 'cryptogovernance', in which trust, law and enforcement are outsourced to computer code." The post-political challenges of implementing 'SusTech' - technology that blends cryptography and sustainability - emerge here as entirely technical; a matter of hardware efficiency, developing and distributing technical dictionaries, and replacing legal protections with smart contracts written in computer code. The rest of this section will consider the flaws to these arguments in relation to automated trust protocols for REDD+ governance, specifically around managing access to project benefits.

With many REDD+ projects to date, there have been gaps between proposed intentions and reality (Howson, 2017). Especially with regards to access to benefits, including financial compensation payments. Some projects have highlighted the conditional nature of their commitments explicitly. For example, the Clinton Climate Initiative envisioned their Sungai Lamandau project as a communityforestry empowerment project with a potential REDD+ 'bonus' (Howson and Kindon, 2015). This potential bonus would take the form of a direct financial payment to members of local community groups, payable upon the sale of the project's carbon credits, should a buyer ever materialise. Proposals behind the EarthToken ${ }^{15}$ cryptocarbon initiative, built on Ethereum smart contracts, have proved more misleading (Sullivan, 2018). The initiative originally stated their intent towards incentivising forest communities living in and around Zimbabwe's Kariba REDD+ project site, via their native token. EarthToken ${ }^{16}$ states that, "People just like you can invest in a sustainable future and share in the success of this enormous opportunity" (see Figure 2). However, no transfer of tokens has been, or could ever be, made within the current global governance regime of crypto-commodity markets.

\footnotetext{
${ }^{15} \mathrm{https}: / /$ earth-token.com/

${ }^{16}$ https://youtu.be/KnksfHe-fag
} 

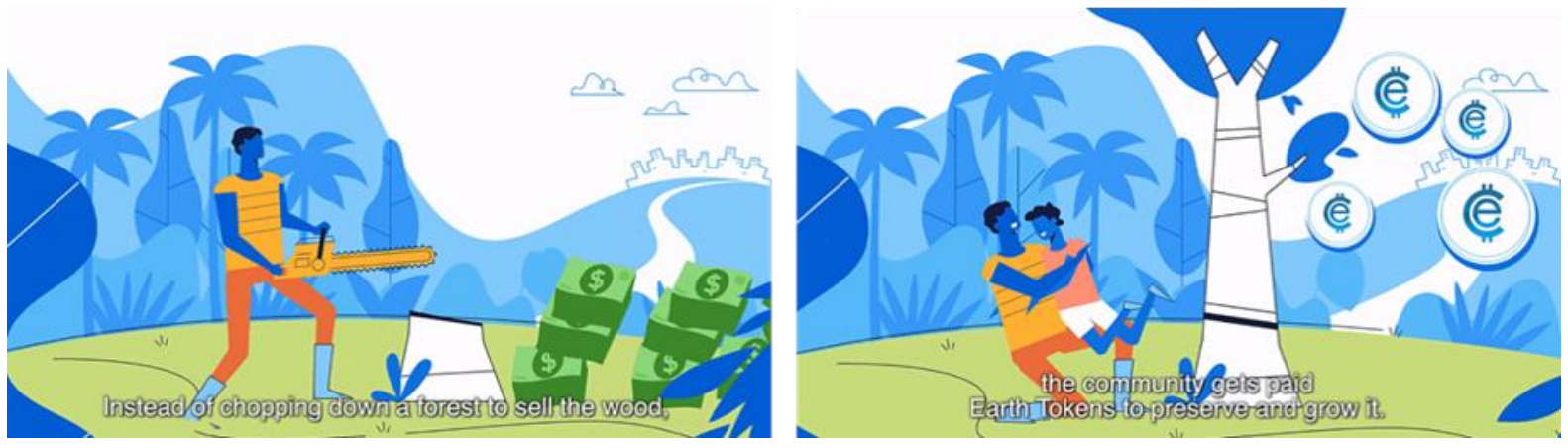

Figure 2: Screen shots from EarthToken's explainer video (Source: YouTube)

The broken promise relates to EarthToken's conditions specifically excluding investors from 'high-risk' jurisdictions, as defined by the US Department of the Treasury's Financial Action Task Force and Office of Foreign Assets Control, which includes Zimbabwe. (Lang, 2018; Sullivan, 2018). Other cryptocarbon projects have tended to promote their promises through whitepaper proposal documents, giving a detailed summary of the implementers' respective use case. However, these claims tend to be aspirational. For example, XYO network's whitepaper proposes the launch of two 'low-earth-orbit satellite sentinels' by 2019. Veridium proposes a less ambitious roadmap. Their Verde token will be tied to an established REDD+ project, and their management and advisory panel includes well-known names, such as Infinite Earth co-founder, Todd Lemons and US broadcaster, CNBC's Fast Money host, Brian Kelly. However, despite the efforts of blockchain project implementers to appear legitimate, according to Benedetti and Kostovetsky (2018), most blockchain ventures fail to achieve their stated objectives. 66 percent of blockchain projects that raise funds through public ICOs, fail to form functioning projects.

Participation in autonomous cryptocarbon governance frameworks is defined by property relations, and a belief that parties always act to further their private self-interest (Chapron, 2017). Members must buy shares in the project, in the form of tokens, while the platform maintains a system of incentive payments. Smart contracts running on Ethereum, for example, pay a sum of Ether to the network node that executes that contract. Yet, these incentive structures are unlikely to encourage any new form of mutuality beyond quid pro quo forms of market exchange. They maintain social disconnections and mistrust 'away from keyboard'. As the founder of the Ethereum Network, Vitalik Buterin explains, organisations run on smart contracts are just like any other human organisation. "In general, a human organisation can be defined as a combination of two things: a set of property, and a protocol for a set of individuals, which may or may not be divided into certain classes with different conditions for entering" (in Greenfield, 2017 p161). Promoting a human-non-human conviviality is not the objective for such a governance framework. The cryptocarbon fix is encoded with market-based principles. A blockchain-based solution for climate change will always maintain the coupling between the non-human and market environmentalism. Both REDD+ and cryprocarbon projects require unfathomably complex forest ecosystems to be simplified into discrete processes and objects in order to define, standardise, and universally agree on their carbon content and value of the associated service provision (Boyd, 2009). Such monetary valuation remains ultimately about advancing capitalist forms of governance, which not only leads to an oversimplification of ecological complexity, but further embeds neoliberal ideologies in global solutions for environmental crisis (Matulis, 2015). 


\section{Conclusions}

Despite promises of transforming the opaque world of climate finance (Marke, 2018), like any powerful technology, the social and political costs and benefits of nascent blockchain applications remain ambiguous. This paper has considered how blockchain is providing various opportunities for the REDD+ mechanism, as well as the new challenges caused by such 'crypto-fixes'. We have looked specifically at four of the ways blockchain is being leveraged to engage persistent faults of REDD+. These have included: 1) lack of public interest leading to unsustainable funding, 2) deficient MRV regimes, 3) inequitable distribution of project costs and benefits, and 4) failure to secure rights for forest dependent and indigenous communities. We have also focused on the environmental governance challenges relating to cryptocarbon initiatives. The nature of these challenges stem from the way REDD+ was originally conceived, as a way to address the global problem of climate change by incentivising forest protection in developing countries. Implementing REDD+ has proven slower, costlier, as well as more technically and socially challenging than originally expected (Sunderlin et al., 2014, Lund et al, 2017). In terms of reducing deforestation and forest degradation, REDD+ has "fallen far short of what was hoped." (Sills et al., 2014 p4). Some have argued that REDD+ has become a conservation fad (Redford et al., 2013; Lund et al, 2017) allaying fears of imminent 'green grabbing' en masse that many had expected (Fairhead et al., 2012; Lund et al., 2017). Despite the vigilance of critical scholars committed to enabling equitable outcomes in sites of REDD+ implementation, with a few exceptions (e.g. Lang, 2018; Sulliavan, 2018) the various manifestations of blockchain for REDD+ that this paper has explored, have so far proved of limited critical concern.

We argue that through the convergence of blockchain and forest protection comes a need for more case-specific exposition. Previous insights from critical scholars emphasised the unpredictability of the REDD+ programme, and the importance of place in shaping how the multiplicity of REDD+ activities were being received, interpreted and implemented (McGregor, et al, 2014). Blockchain-based conservation has so far lacked the authoritative scholarly analysis it deserves. As this field of scholarship develops, a practical critique will prove essential for understanding the particularities of each intervention. Mance (2018) suggests that scholars of environmental management could ignore this technology, and hope that the Tech Optimists focus their energies on Mars. Alternatively, researchers can understand and critique blockchain applications to enable desirable outcomes. As Harian (2018) argues, understanding the ideological parameters in which blockchain applications operate, and the commercial and individual interests that the technology channels, is vital in order to cut through problematic hype, whilst challenging hollow sentiments of entrepreneurial 'disruption'. Blockchain algorithms, big data, and Al will continue to shape human relationships over the coming decades. We should expect them to shape our relationships with forests too. 


\section{References}

Al-Saqaf, W. \& Seidler, N. (2017) Blockchain technology for social impact: opportunities and challenges ahead, Journal of Cyber Policy, 2:3, 338-354

Angelsen, A., M. Brockhaus, W. Sunderlin, and L. Verchot. (2012). Analysing REDD+: challenges and choices. Bogor: CIFOR.

Angelsen, A., Brockhaus, M., Duchelle, A., Larson, A., Martius, C., Sunderlin, W., Verchot, L., Wong, G. and Wunder, S. (2017). Learning from REDD+: a response to Fletcher et al. Conservation Biology, 31(3): 718-720.

Barr, C. and Sayer, J. (2012). The political economy of reforestation and forest restoration in AsiaPacific: Critical issues for REDD+. Biological Conservation, 154: 9-19.

Barletti, J. and Larson, A. (2017). Rights abuse allegations in the context of REDD+ readiness and implementation: A preliminary review and proposal for moving forward. Bogor: CIFOR

Benedetti, H. and Kostovetsky, L. (2018). Digital Tulips? Returns to Investors in Initial Coin Offerings. Accessed Online at https://poseidon01.ssrn.com/ (21.06.2018)

Boyda, E., Basu, S., Ganguly, S., Michaelis, A., Mukhopadhyay, S. and Nemani, R. (2017). Deploying a quantum annealing processor to detect tree cover in aerial imagery of California. PLOS ONE, 12(2): 122

Cavanagh, C. and T. Benjaminsen. (2014). Virtual nature, violent accumulation: the "spectacular failure" of carbon offsetting at a Ugandan National Park. Geoforum 56(1): 55-65.

Chapron, G. (2017). The environment needs cryptogovernance. Nature, 545(7655): 403-405.

Conley, J. (2017). Blockchain and the Economics of Crypto-tokens and Initial Coin Offerings, Vanderbilt University Department of Economics Working Papers 17-00008, Vanderbilt University Department of Economics.

Connolly, L., Drazen, E., Eickhoff, G., Graham, P., Thoumi, G., Wardwell, D. (2017) The missing link: how a distributed ledger system can support global climate action. [online] Available at: https://www.climateadvisers.com/wp-content/uploads/2017/11/FINAL-The-Missing-Link-How-ADistributed-Ledger-System-Can-Support-Global-Climate-Action.pdf [Accessed 8 Dec. 2018].

Digiconomist (2018) Bitcoin Energy Consumption Index. [online] Available at: https://digiconomist.net/bitcoin-energy-consumption [Accessed 8 Dec. 2018].

Duchelle, A.E., Simonet, G., Sunderlin, W.D., Wunder, S. (2018) What is REDD+ achieving on the ground? Current Opinion in Environmental Sustainability, 32: 134-140

Dupont, Q. (2017). Blockchain Identities: Notational Technologies for Control and Management of Abstracted Entities. Metaphilosophy, 48(5): 634-653.

Enrici, A. M., and K. Hubacek. (2018). Challenges for REDD+ in Indonesia: a case study of three project sites. Ecology and Society 23(2):7 
Evans, K. (2017). It's too soon to bury REDD+ - CIFOR Forests News. [online] CIFOR Forests News. Available at: https://forestsnews.cifor.org/49642/its-too-soon-to-bury-redd?fnl=en [Accessed 3 Aug. 2017].

Fletcher, R., Dressler, W., Büscher, B. and Anderson, Z. (2016). Questioning REDD+ and the future of market-based conservation. Conservation Biology, 30(3): 673-675.

FOAM (2018). FOAM Whitepaper. [online] Available at: https://foam.space/ [Accessed 3 Aug. 2018].

KFNX (2018) The Crypto Show: Connie Gallippi On BitGive And Their Latest Efforts [online] Available at: https://letstalkbitcoin.com/blog/post/the-crypto-show-connie-gallippi-on-bitgive-and-theirlatest-efforts [Accessed 8 Nov 2018].

Gizachew, B., R. Astrup, P. Vedeld, E. Zahabu, and L. Duguma (2017). REDD+ in Africa: contexts and challenges. Natural Resources Forum, 41, pp. 92-104

Government of Indonesia (2016). First nationally determined contribution Republic of Indonesia. [online] Available

at: http://www4.unfccc.int/ndcregistry/PublishedDocuments/Indonesia\%20First/First\%20NDC\%20Indo nesia_submitted\%20to\%20UNFCCC\%20Set_November\%20\%202016.pdf [Accessed 3 Jun. 2018].

Green, A (2018) Satellites, lasers and undersea bots track world carbon stocks. Financial Times. 29 March, 2018 https://www.ft.com/content/6df2befe-cb00-11e7-8536-d321d0d897a3.

Greenfield, A. (2017). Radical Technologies. London: Verso.

Gupta, V. (2017). A Brief History of Blockchain. [online] Harvard Business Review. Available at: https://hbr.org/2017/02/a-brief-history-of-blockchain [Accessed 3 Aug. 2018].

Hamrick, K. (2017). State of the Voluntary Carbon Markets 2017. Ecosystem Marketplace. Accessed Online at https://www.cbd.int/financial/2017docs/carbonmarket2017.pdf (01.06.2018)

Howson, P. (2017) Intimate exclusions from the REDD+ benefits of Sungai Lamandau, Central Kalimantan, Indonesia. Conservation \& Society, 15(2): 125-135.

Howson, P. (2018) Slippery Violence in the REDD+ Forests of Central Kalimantan, Indonesia. Conservation \& Society 16(2): 136-146.

Howson, P. \& S. Kindon (2015) Analysing access to the local REDD+ benefits of Sungai Lamandau, Central Kalimantan, Indonesia, Asia Pacific Viewpoint, 56(1): 96-110.

Huckle, S. and White, M. (2016) Socialism and the Blockchain. Future Internet, 8(4), 49

Kshetri, N. (2017). Will blockchain emerge as a tool to break the poverty chain in the Global South?. Third World Quarterly, 38(8), pp.1710-1732.

Labbate, G. (2017). A win-win solution for the aviation industry and REDD+. [online] UN-REDD Programme. Available at: http://www.un-redd.org/single-post/2017/12/28/A-win-win-solution-forthe-aviation-industry-and-REDD [Accessed 8 Nov 2018]

Lang, C. (2018). The Kariba REDD project in Zimbabwe: From carbon credits to EARTH tokens. [online] REDD-monitor.org. Available at: http://www.redd-monitor.org/2018/02/08/the-kariba-redd-projectin-zimbabwe-from-carbon-credits-to-earth-tokens/ [Accessed 3 Aug. 2018]. 
Larson, A., Brockhaus, M., Sunderlin, W., Duchelle, A., Babon, A., Dokken, T., Pham, T., Resosudarmo, I., Selaya, G., Awono, A. and Huynh, T. (2013). Land tenure and REDD+: The good, the bad and the ugly. Global Environmental Change, 23(3), pp.678-689.

Lin, L., Sills, E. and Cheshire, H. (2014). Targeting areas for Reducing Emissions from Deforestation and forest Degradation (REDD+) projects in Tanzania. Global Environmental Change, 24, pp.277-286.

Lindhjem, H., I. Aronsen, K. G. Bråten, and A. Gleinsvik. (2010). Experiences with benefit sharing: issues and options for REDD+. Oslo: Pöyry.

Lohmann, L. (2010). Uncertainty Markets and Carbon Markets: Variations on Polanyian Themes. New Political Economy, 15(2), pp.225-254.;

Luttrell, C., Resosudarmo, I., Muharrom, E., Brockhaus, M. and Seymour, F. (2014). The political context of REDD+ in Indonesia: Constituencies for change. Environmental Science \& Policy, 35, pp.6775.

Mance, H. (2018). Algorithmic wilderness: Robo-bees and drone-seeded forests: can technology mend our broken relationship with the natural world? [Online] Accessed at https://aeon.co/essays/techbroke-our-relationship-with-wilderness-can-it-mend-it-too [11 Nov 2018]

Marke, A. (2018). Transforming Climate Finance and Green Investment with Blockchains. Cambridge, MA: Academic Press.

Matulis, B. S. (2015). Valuing Nature: A Reply to Esteve Corbera. Ecological Economics (110): 158-160

McGregor, A (2010) Green and REDD? Towards a political ecology of deforestation in Aceh, Indonesia. Human Geography, 3(2): 21-34

McGregor. A, E. Challies, P. Howson, R. Astuti, R. Dixon, B. Haalboom, M. Gavin, L. Tacconi \& S. Afiff (2014) Beyond carbon, more than forests: REDD+ governmentality in Indonesia. Environment \& Planning A, 47(1): 138-155.

McGregor. A, S. Weaver, E. Challies, P. Howson, R. Astuti \& B. Haalboom (2014) Practical critique: Bridging the gap between critical and practice oriented REDD+ research communities. Asia Pacific Viewpoint, 55(3): 277-291.

Milne, S., Mahanty, S., To P., Dressler W., Kanowski P., Thavat M. (2019) Learning from 'actually existing' REDD+: A synthesis of ethnographic findings. Conservation and Society. 17(1):84-95.

Milne, S. and E. Niesten (2009) Direct payments for biodiversity conservation in developing countries: Practical insights for design and implementation, Oryx 43(4): 530-541

Mora, C., Randi L. Rollins, Katie Taladay, Michael B. Kantar, Mason K. Chock, Mio Shimada \& Erik C. Franklin (2018) Bitcoin emissions alone could push global warming above $2^{\circ} \mathrm{C}$. Nature, Climate Change, $8931-933$

Nel, A. (2014). Zones of Awkward Engagement in Ugandan Carbon Forestry. In: Carbon Conflicts and Forest Landscapes in Africa (eds. Leach, M. and I. Scoones). 1st edition. Pp. 94-107. New York: Routledge. 
O'Neil (2016). Weapons of math destruction: How big data increases inequality and threatens democracy. NY: Random House

Oprunenco, A. and Akmeemana, C. (2018). Using blockchain to make land registry more reliable in India. [online] South Asia @ LSE. Available at: http://blogs.Ise.ac.uk/southasia/2018/05/18/usingblockchain-to-make-land-registry-more-reliable-in-india/ [Accessed 3 Aug. 2018].

Redford K, Padoch C, Sunderland T. (2013). Fads, funding, and forgetting in three decades of conservation. Conservation Biology 27: 437-438.

Regen.Network (2017). Regen.Network Whitepaper. [online] Available at: https://www.regen.network/ [Accessed 3 Aug. 2018].

Schneider, L. and Kollmuss, A. (2015). Perverse effects of carbon markets on HFC-23 and SF6 abatement projects in Russia. Nature Climate Change. 5, 1061-1063

Sullivan, S. (2009) Green capitalism. Radical Anthropology, 3, 18-27

Sullivan, S. (2018) Nature 3.0 - Will blockchain technology and cryptocurrencies save the planet? [online] Available at: https://entitleblog.org/2018/02/01/nature-3-0-will-blockchain-technology-andcryptocurrencies-save-the-planet/ [Accessed 8 Nov 2018]

Sunderlin, W. D., and E. O. Sills. (2012). REDD+ projects as a hybrid of old and new forest conservation approaches. Pages 177-191 in A. Angelsen, M. Brockhaus, W. D. Sunderlin, and L. V. Verchot, editors. Analysing REDD+: challenges and choices. Center for International Forestry Research, Bogor, Indonesia.

Terra0 (2018). Terra0 - Flowertokens. [online] Available at: https://flowertokens.terra0.org/info/ [Accessed 3 Aug. 2018].

Thompson, B. (2017). Can Financial Technology Innovate Benefit Distribution in Payments for Ecosystem Services and REDD+? Ecological Economics, 139: 150-157.

Wytze van der Gaast, Richard Sikkema \& Moriz Vohrer (2018) The contribution of forest carbon credit projects to addressing the climate change challenge, Climate Policy, 18:1, 42-48, DOI: 10.1080/14693062.2016.1242056

World Bank, (2017). State and Trends of Carbon Pricing 2017. Accessed Online at http://documents.worldbank.org/curated/en/468881509601753549/pdf/120810-REVISED-PUBPUBLIC.pdf (31.05.2018)

Zeebe, R. E., Ridgwell, A., and Zachos, J. C. (2016) Anthropogenic carbon release rate unprecedented during the past 66 million years. Nature Geoscience. 9: 325-329 